\title{
The pulse pressure in a premature infant less than 37 weeks gestational age with a patent ductus arteriosus
}

\author{
Cristina Vega-Barrera ${ }^{1}$, Jonathan Muraskas ${ }^{1}$, Rong Guo ${ }^{2}$, Brooke Ray ${ }^{3}$ \\ ${ }^{1}$ Neonatal Intensive Care Unit, Loyola University Medical Center, Maywood, USA \\ ${ }^{2}$ Statistics Department, Loyola University Medical Center, Maywood, USA \\ ${ }^{3}$ Illinois Mathematics and Science Academy, Aurora, USA \\ Email: cbaumker@lumc.edu, jmurask@lumc.edu
}

Received 15 January 2013; revised 19 February 2013; accepted 28 February 2013

Copyright (C) 2013 Cristina Vega-Barrera et al. This is an open access article distributed under the Creative Commons Attribution License, which permits unrestricted use, distribution, and reproduction in any medium, provided the original work is properly cited.

\begin{abstract}
A widened pulse pressure could be a sign of a patent ductus arteriosus in an infant. This is defined as a difference between systolic and diastolic blood pressure of greater than 15 to $25 \mathrm{~mm} \mathrm{Hg}$, in premature infants and greater than $25 \mathrm{~mm} \mathrm{Hg}$ in term infants [1]. It is thought that diastolic runoff from blood flow shunting across the aorta to the pulmonary artery, through the patent ductus arteriosus, will produce a lower diastolic pressure and therefore widen the pulse pressure in the affected infant [1]. In our retrospective chart review, 116 premature infants were identified with a patent ductus arteriosus and compared to 42 premature infants without a patent ductus arteriosus. The blood pressures obtained were recorded for the first 7 days of life of the patients. Our studies revealed that premature infants with a patent ductus arteriosus had a mean pulse pressure of $19 \mathrm{~mm} \mathrm{Hg}$ (p-value 0.129) when compared to infants without a patent ductus arteriosus, $16 \mathrm{~mm} \mathrm{Hg}$, on day 1 of life. The mean pulse pressures were $\sim 20 \mathrm{~mm} \mathrm{Hg}$ in both groups on days 2 - 3. On days 4 - 7 mean pulse pressures were greater than $20 \mathrm{~mm} \mathbf{~ H g}$ for both groups (p-values $0.35,0.19,0.74,0.8)$. It was noticed that mean pulse pressures in the patent ductus arteriosus group were within $\mathrm{O}-4 \mathrm{~mm} \mathrm{Hg}$ when compared to the group without a patent ductus arteriosus and therefore not clinically relevant or statistically significant.
\end{abstract}

Keywords: Patent Ductus Arteriosus; Widened Pulse Pressure; Premature

\section{INTRODUCTION}

A premature infant with a patent ductus arteriosus (PDA) is a common occurrence. Nearly $30 \%$ of premature infants with birth weight less than 1500 grams will have a PDA [2]. In a premature infant, the diagnosis of a hemodynamically significant ductus arteriosus in a timely manner would lead to early treatment of this condition and prevent complications such as pulmonary edema/ overflow and respiratory failure [3]. A formal diagnosis of a PDA is typically made with a Doppler echocardiogram. The echocardiogram will identify the patent ductus arteriosus and allow the neonatologist to initiate treatment either through medical or surgical intervention. In a term neonate a patent ductus arteriosus is not a problem. The neonate will transit in the first few days of life and the PDA will constrict and functionally close. In the preterm infant, a PDA may not functionally close due to immaturity of the ductal chemical mediators and hypoxemia the infant undergoes from premature lung disease [2]. Thus having a PDA could lead to complications such as decreased lung compliance, pulmonary edema/ overflow, respiratory failure [3] and heart failure from volume overload into the left side of the heart.

For the past 25 years of neonatal medicine, the goal has been to effectively diagnose a PDA in premature infants, through clinical and/or interventional techniques such as echocardiogram, treat the condition, reduce the duration of ventilator days, and therefore decrease the incidence of bronchopulmonary dysplasia [4]. The clinical diagnosis of a PDA has been historically taught in medical schools and residency programs to be a high para-sternal systolic murmur, hyperdynamic precordial impulse, bounding pulses, and a widened pulse pressure [5]. Evans et al. demonstrated that a widened pulse pressure is not seen in preterm infants with a PDA [6]. In this study by Evans, 41 subjects were evaluated in the first 7 days of life who were $<1500$ grams with serial echocardiograms and continuous intra-arterial blood pressure monitoring. It was noticed that infants whose birth 
weights were between 1000 - 1500 grams with a hemodynamic significant PDA did not have a significant difference in mean systolic, diastolic or pulse pressures when compared to those without a PDA [6]. There was a significant difference in systolic, diastolic and mean blood pressures in 8 infants $<1000$ grams with a PDA, when compared to those without a PDA, but mean pulse pressures again were not different in both groups [6].

\section{SUBJECTS AND METHODS}

We conducted a retrospective chart review of premature infants born at Loyola University Medical Center between August 15, 2006 and August 15, 2010. Infants included into the study were born premature, less than 37 weeks gestational age, had no congenital heart disease or major birth defects, and had medical charts in electronic version. There were 689 patients with complete medical charts identified beginning January 1, 2008 through December 15, 2010 in the EPIC computerized database. 419 patients did not have an echocardiograph performed. 7 patients were excluded due to congenital heart disease. The total patients reviewed were 263 (Table 1). Of the 263 patients reviewed, 158 patients had invasive blood pressure measurements available for analysis. 116 patients had a documented PDA and 42 did not have a PDA. We recorded the following data on infants who met the criteria (Table 2). The data included: identifying factors such as name, medical record number, DOB, gestational age, race, birth weight, mother's mode of delivery, gender, APGAR scores at 1 and 5 minutes, complications such as intraventicular hemorrhage (IVH), necrotizing enterocolitis (NEC), steroids prenatally given, and vital signs. The vital signs reviewed were systolic blood pressures (SBP), diastolic blood pressures (DBP), mean arterial blood pressures (MAP) from day of life 1 through 7. (Table 3) The pulse pressure was calculated using the recorded diastolic pressure and systolic blood pressures Eq.1.

$$
\mathrm{PP}=\mathrm{SBP}-\mathrm{DPB} \text {. }
$$

We further subdivided the vital signs data into invasive blood pressures taken through a continuous monitoring arterial line versus a non-invasive blood pressure taken from a pressure cuff. The arterial lines were either peripherally inserted into an extremity or a UAC line; we did not distinguish between the two. We only used invasive blood pressures for the analysis. Our aim was to record 6 blood pressures per day of life for the first 7 days of life on each patient. However, some patients only had from 0 - 6 blood pressures recorded per patient per day for invasive blood pressure measurements. This was due to removal of the arterial line.

All patients in this study had an echocardiogram performed, and results documented into our database in-
Table 1. Total number of infants in study.

\begin{tabular}{ccccc}
\hline Year & Total & $\begin{array}{r}\text { PDA by } \\
\text { ECHO }\end{array}$ & $\begin{array}{c}\text { No PDA } \\
\text { by ECHO }\end{array}$ & $\begin{array}{c}\text { ECHO } \\
\text { not done }\end{array}$ \\
\hline 2008 & 278 & 56 & 36 & 186 \\
2009 & 262 & 61 & 43 & 158 \\
2010 & 149 & 43 & 31 & 75 \\
$(2008-2010)$ & 689 & 160 & 110 & 419 \\
$\begin{array}{c}\text { excluded } \\
\text { (did not meet criteria) }\end{array}$ & & 4 & 3 & \\
$\begin{array}{c}\text { Total (2008-2010) } \\
\text { Total Reviewed- }\end{array}$ & & 156 & 107 & \\
(2008-1010) with & & 116 & 42 & \\
invasive BP & & & & \\
\hline
\end{tabular}

Table 2. Characteristics of infants.

\begin{tabular}{ccc}
\hline & No PDA & PDA \\
\hline Gestational age (mean) & 30.2 weeks & 29.7 weeks \\
Birth weight (mean) & 1551 grams & 1273 grams \\
Gender male & 64 & 97 \\
Gender female & 43 & 59 \\
NEC all stages & 13 & 14 \\
IVH all grades & 10 & 10 \\
\hline
\end{tabular}

cluding the day of the infant's life it was performed; if an echocardiogram was not performed the patient was excluded from the study. We did not document the velocities of shunts, or direction of shunts.

\section{Data Analysis}

The blood pressure measurements were recorded in excel document and analysis through a two-sample t test was performed and results shown (Table 3). The infants were grouped into a PDA group vs. the no PDA group. There were 116 subjects in the PDA group and 42 subjects in the no PDA group. The blood pressures were statistically analyzed against the day the echocardiogram confirmed the presence of PDA or no PDA in the patient (Figures 1-4).

\section{RESULTS}

\subsection{Systolic Blood Pressures (Figure 1)}

Invasive systolic blood pressures were obtained for 116 patients with PDA and 42 without a PDA and plotted against days 1 through 7 . There was no significant difference is systolic blood pressures between both groups. The mean systolic blood pressures were $50 \mathrm{~mm} \mathrm{Hg}$ and $51 \mathrm{~mm} \mathrm{Hg}$ in the PDA vs. no PDA group ( $\mathrm{p}=0.865)$ on day 1 and $48 \mathrm{~mm} \mathrm{Hg}$ and $49 \mathrm{~mm} \mathrm{Hg}$ on day 2 ( $\mathrm{p}=0.92)$. On day 3, the PDA group had a lower systolic pressure 
Table 3. A comparison of blood pressures between PDA and no PDA by day.

\begin{tabular}{|c|c|c|c|c|c|c|c|c|}
\hline Day & Measurement & Group & $\mathrm{N}$ & Mean & Std Deviation & Minimum & Maximum & $\mathrm{p}$ value \\
\hline \multirow{10}{*}{1} & \multirow{2}{*}{ DBP } & No PDA & 2 & 35.8350 & 13.6684 & 26.1700 & 45.5000 & \multirow{2}{*}{0.5055} \\
\hline & & PDA & 12 & 31.2500 & 8.1525 & 21.8300 & 50.0000 & \\
\hline & \multirow{3}{*}{ MAP } & No PDA & 2 & 41.1650 & 12.4946 & 32.3300 & 50.0000 & \multirow{3}{*}{0.7670} \\
\hline & & & & & & & & \\
\hline & & PDA & 12 & 39.0142 & 8.9433 & 30.0000 & 60.5000 & \\
\hline & \multirow{3}{*}{ SBP } & No PDA & 2 & 51.7500 & 13.5482 & 42.1700 & 61.3300 & \multirow{3}{*}{0.8652} \\
\hline & & & & & & & & \\
\hline & & PDA & 12 & 50.2908 & 10.7525 & 35.6700 & 71.3300 & \\
\hline & \multirow[b]{2}{*}{ pp } & No PDA & 2 & 15.9150 & 0.1202 & 15.8300 & 16.0000 & \multirow{2}{*}{0.1291} \\
\hline & & PDA & 12 & 19.0417 & 6.5966 & 8.5000 & 30.5000 & \\
\hline \multirow{10}{*}{2} & \multirow{2}{*}{ DBP } & No PDA & 5 & 28.5660 & 3.3443 & 26.0000 & 33.0000 & \multirow{2}{*}{0.8263} \\
\hline & & PDA & 16 & 27.7869 & 7.4945 & 15.1700 & 43.1700 & \\
\hline & \multirow{3}{*}{ MAP } & No PDA & 5 & 37.5680 & 5.1796 & 33.1700 & 45.0000 & \multirow{3}{*}{0.6983} \\
\hline & & & & & & & & \\
\hline & & PDA & 16 & 36.0350 & 8.1271 & 26.1700 & 53.5000 & \\
\hline & \multirow{3}{*}{ SBP } & No PDA & 5 & 48.8340 & 7.0468 & 43.5000 & 59.6700 & \multirow{3}{*}{0.9218} \\
\hline & & & & & & & & \\
\hline & & PDA & 16 & 48.3438 & 10.1913 & 32.1700 & 68.0000 & \\
\hline & \multirow[b]{2}{*}{ pp } & No PDA & 5 & 20.2680 & 3.8317 & 17.5000 & 26.6700 & \multirow{2}{*}{0.9245} \\
\hline & & PDA & 16 & 20.5569 & 6.3073 & 7.3300 & 32.1700 & \\
\hline \multirow{10}{*}{3} & \multirow{2}{*}{ DBP } & No PDA & 7 & 36.7857 & 12.8450 & 28.6700 & 64.8300 & \multirow{2}{*}{0.0671} \\
\hline & & PDA & 17 & 25.8829 & 4.9734 & 20.0000 & 39.6700 & \\
\hline & \multirow{3}{*}{ MAP } & No PDA & 7 & 44.5229 & 12.9709 & 37.3300 & 73.3300 & \multirow{3}{*}{0.1013} \\
\hline & & & & & & & & \\
\hline & & PDA & 17 & 34.9012 & 5.9291 & 25.6700 & 50.8300 & \\
\hline & \multirow{3}{*}{ SBP } & No PDA & 7 & 56.5700 & 13.4987 & 44.8300 & 85.8300 & \\
\hline & & & & & & & & 0.0428 \\
\hline & & PDA & 17 & 46.9024 & 8.3379 & 33.5000 & 65.6700 & \\
\hline & & No PDA & 7 & 19.7843 & 3.3331 & 12.8300 & 22.8300 & \\
\hline & pp & PDA & 17 & 21.0206 & 4.6697 & 13.1700 & 29.1700 & 0.5330 \\
\hline & & No PDA & 10 & 31.5830 & 10.8293 & 18.3300 & 54.8300 & \\
\hline & DDF & PDA & 22 & 25.4318 & 8.9047 & 14.8300 & 57.5000 & $0.100 /$ \\
\hline & & No PDA & 10 & 40.8840 & 11.0071 & 28.1700 & 65.6700 & \\
\hline & MAP & & & & & & & 0.1405 \\
\hline 4 & & PDA & 22 & 35.1664 & 9.3905 & 25.5000 & 70.0000 & \\
\hline & & No PDA & 10 & 53.5010 & 12.1030 & 39.6700 & 80.1700 & \\
\hline & SBP & & & & & & & 0.3146 \\
\hline & & PDA & 22 & 49.1518 & 10.7157 & 38.3300 & 87.0000 & \\
\hline & & No PDA & 10 & 21.9170 & 5.6873 & 9.0000 & 28.8300 & \\
\hline & pp & PDA & 22 & 23.7191 & 4.7003 & 9.8300 & 29.5000 & 0.3538 \\
\hline
\end{tabular}




\section{Continued}

\begin{tabular}{|c|c|c|c|c|c|c|c|c|}
\hline \multirow{9}{*}{5} & \multirow{2}{*}{ DBP } & No PDA & 5 & 29.7660 & 5.8407 & 20.5000 & 36.3300 & \multirow{2}{*}{0.1246} \\
\hline & & PDA & 21 & 25.6395 & 5.0752 & 17.5000 & 35.0000 & \\
\hline & \multirow{3}{*}{ MAP } & No PDA & 6 & 39.1383 & 7.4982 & 25.8300 & 48.6700 & \multirow{3}{*}{0.3034} \\
\hline & & & & & & & & \\
\hline & & PDA & 21 & 35.9448 & 6.3112 & 26.8300 & 49.0000 & \\
\hline & \multirow{2}{*}{ SBP } & No PDA & 5 & 52.2000 & 11.1272 & 32.8300 & 60.0000 & \multirow{2}{*}{0.8810} \\
\hline & & PDA & 21 & 51.5324 & 8.3428 & 33.1700 & 67.0000 & \\
\hline & \multirow[b]{2}{*}{ pp } & No PDA & 5 & 22.4340 & 5.9712 & 12.3300 & 27.6700 & \multirow{2}{*}{0.1929} \\
\hline & & PDA & 21 & 25.8919 & 5.0154 & 11.3300 & 34.5000 & \\
\hline \multirow{9}{*}{6} & \multirow[b]{2}{*}{ DBP } & No PDA & 4 & 30.5850 & 4.0664 & 26.1700 & 35.6700 & \multirow[b]{2}{*}{0.5743} \\
\hline & & PDA & 18 & 27.3433 & 11.0049 & 17.0000 & 66.5000 & \\
\hline & \multirow{2}{*}{ MAP } & No PDA & 4 & 39.9600 & 5.4421 & 34.1700 & 47.1700 & \multirow{2}{*}{0.6630} \\
\hline & & PDA & 18 & 37.2411 & 11.8438 & 27.0000 & 79.0000 & \\
\hline & \multirow{3}{*}{ SBP } & No PDA & 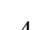 & & 70487 & 466700 & 625000 & \multirow{3}{*}{0.9470} \\
\hline & & & & & & & & \\
\hline & & PDA & 18 & 51.7867 & 14.4535 & 38.8300 & 101.3 & \\
\hline & \multirow{2}{*}{ pp } & No PDA & 4 & 21.7075 & 3.4393 & 19.5000 & 26.8300 & \multirow{2}{*}{0.7410} \\
\hline & & PDA & 19 & 23.1574 & 8.3812 & 0 & 36.0000 & \\
\hline \multirow{9}{*}{7} & \multirow{2}{*}{ DBP } & No PDA & 9 & 26.0189 & 4.3962 & 19.1700 & 32.0000 & \multirow{2}{*}{0.4354} \\
\hline & & PDA & 10 & 24.3330 & 4.7615 & 16.3300 & 31.1700 & \\
\hline & \multirow{2}{*}{ MAP } & No PDA & 9 & 35.9622 & 4.7073 & 29.3300 & 42.0000 & \multirow{2}{*}{0.3603} \\
\hline & & PDA & 10 & 33.4840 & 6.5161 & 225000 & 43.1700 & \\
\hline & \multirow{3}{*}{ SBP } & No PDA & 9 & 50.8511 & 6.5490 & 38.5000 & 58.0000 & \multirow{3}{*}{0.5758} \\
\hline & & & & & & & & \\
\hline & & PDA & 10 & 48.5990 & 10.0655 & 33.1700 & 64.8300 & \\
\hline & \multirow{2}{*}{ pp } & No PDA & 9 & 24.8333 & 2.5053 & 19.3300 & 28.1700 & \multirow{2}{*}{0.8093} \\
\hline & & PDA & 10 & 24.2670 & 6.7579 & 15.3300 & 36.6700 & \\
\hline
\end{tabular}

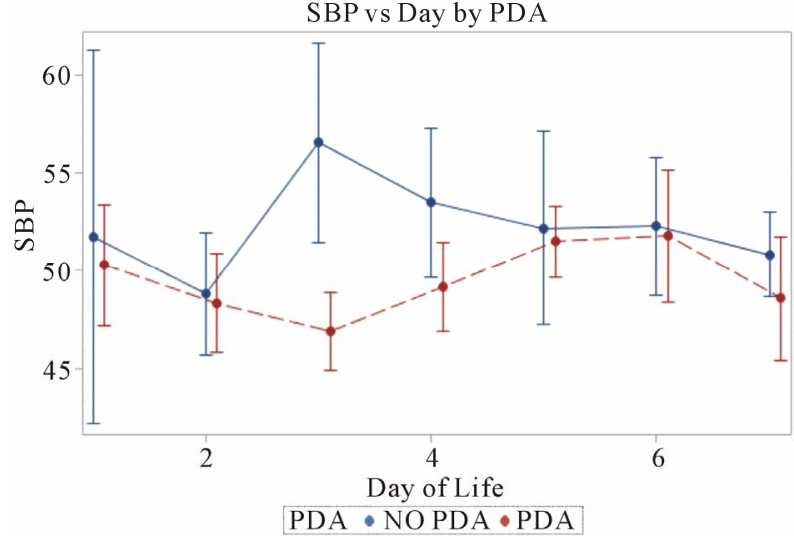

Figure 1. Systolic blood pressures plotted against day of life in the neonate. All patients reviewed were included.

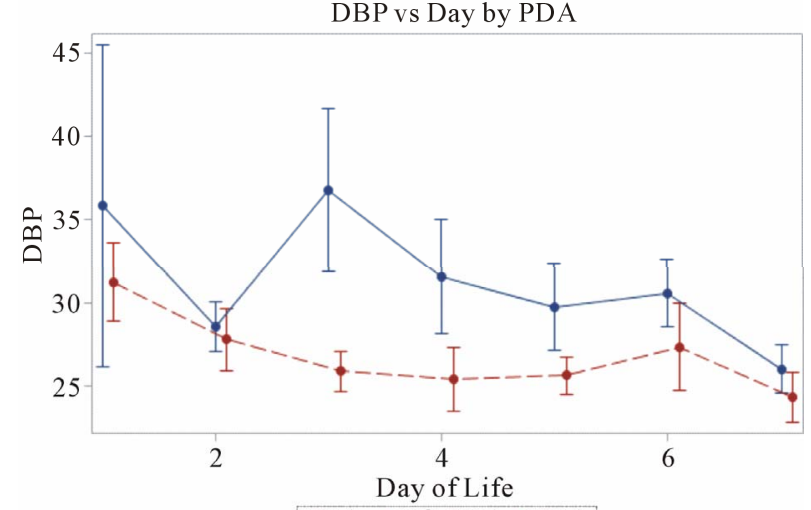

PDA - NOPDA - PDA

Figure 2. Diastolic blood pressures plotted against day of life in the neonate. All patients reviewed were included. 


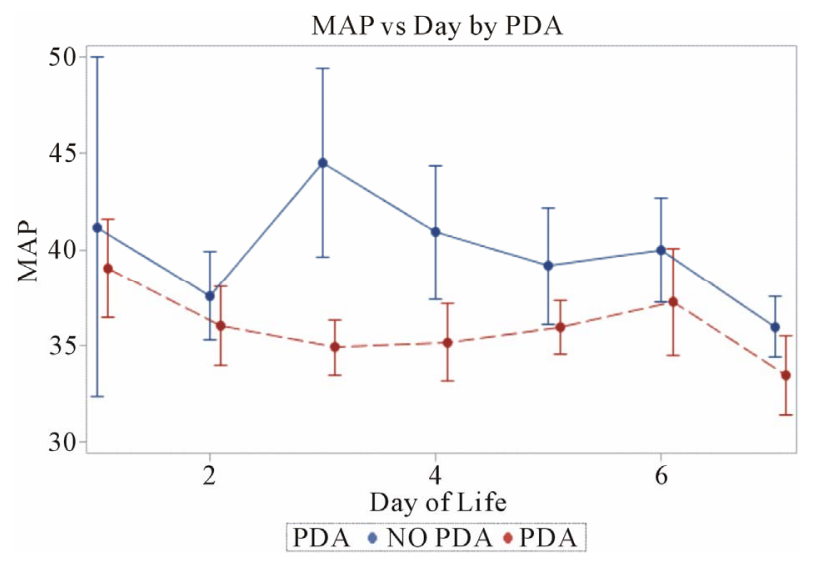

Figure 3. Mean arterial blood pressures plotted against day of life in the neonate. All patients reviewed were included.

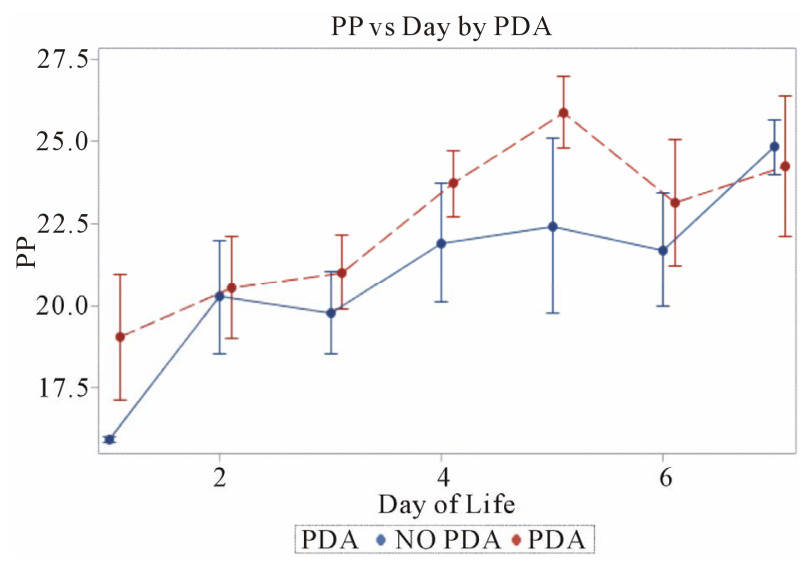

Figure 4. Pulse pressures plotted against day of life in the neonate. All patients reviewed were included.

$47 \mathrm{~mm}$ Hg vs. $57 \mathrm{~mm} \mathrm{Hg}(\mathrm{p}=0.0425)$ when compared to the no PDA group. On days 4 through 7 , both groups had systolic blood pressures within 1 - 4 mm Hg difference and no clinical significance. Overall, the mean systolic blood pressures were the same in both groups, but there was a significant difference of $\sim 10 \mathrm{~mm} \mathrm{Hg}$ only on day 3.

\subsection{Diastolic Blood Pressures (Figure 2)}

Invasive diastolic blood pressures were obtained for 116 patients with PDA and 42 without a PDA on days 1 through 7. The mean diastolic blood pressures were 31 $\mathrm{mm} \mathrm{Hg}$ and $36 \mathrm{~mm} \mathrm{Hg}$ in the PDA vs. no PDA group (p $=0.5$ ) on day 1 and $28 \mathrm{~mm} \mathrm{Hg}$ and $29 \mathrm{~mm} \mathrm{Hg}$ on day 2 $(p=0.8)$. On day 3 , the PDA group had lower diastolic blood pressures when compared to the no PDA group; mean diastolic blood pressure of $25 \mathrm{~mm} \mathrm{Hg}$ vs. $37 \mathrm{~mm}$ $\mathrm{Hg}$ respectively $(\mathrm{p}=0.07)$. This was not clinically significant. The diastolic blood pressures in the PDA group continued to be lower than the no PDA group on day 4 and 5, $25 \mathrm{~mm} \mathrm{Hg}$ vs. $32 \mathrm{~mm} \mathrm{Hg}(\mathrm{p}=0.1$ ) and $26 \mathrm{~mm} \mathrm{Hg}$ vs. $30 \mathrm{~mm} \mathrm{Hg}(\mathrm{p}=0.12)$. Again, the difference was not clinically significant. Between days $6-7$, the mean diastolic blood pressures in the PDA vs. no PDA were 2 - 3 $\mathrm{mm} \mathrm{Hg}$ difference and not significant.

\subsection{Mean Arterial Blood Pressures (Figure 3)}

Invasive average mean arterial blood pressures were obtained for 116 patients with PDA and 42 without a PDA, between days 1 through 7 . The mean mean arterial blood pressures were lower in the PDA group than in the no PDA group on days 3 - 4, $35 \mathrm{~mm} \mathrm{Hg}$ vs. $45 \mathrm{~mm} \mathrm{Hg} \mathrm{(p} \mathrm{=}$ $0.1)$ and $35 \mathrm{~mm} \mathrm{Hg}$ vs. $41 \mathrm{~mm} \mathrm{Hg}(\mathrm{p}=0.1)$ respectively. The mean systolic blood pressures were not significantly different in both groups in days 1 - 7 .

\subsection{Pulse Pressures (Figure 4)}

Pulse pressures were calculated from the invasive blood pressure measurements from both groups. On day 1 , the mean pulse pressure in thepatent ductus arteriosus group was $19 \mathrm{~mm} \mathrm{Hg}$ vs. $16 \mathrm{~mm} \mathrm{Hg}$ in the group without a patent ductus arteriosus $(\mathrm{p}=0.12)$. The mean pulse pressures were greater than or equal to $20 \mathrm{~mm} \mathrm{Hg}$ after day of life 2 reaching a maximum pulse pressure on day of life 5 in both groups. The mean pulse pressure at DOL 5 was $26 \mathrm{~mm} \mathrm{Hg}$ vs. $22 \mathrm{~mm} \mathrm{Hg}$, in the PDA group and no PDA group respectively $(\mathrm{p}=0.19)$. After DOL 5 , mean pulse pressures became similar in the two groups. The mean pulse pressures in the PDA group were 0.3 - $4 \mathrm{~mm}$ Hg higher on days 1 through 7, when compared to the group without a PDA. Both groups had widened pulse pressures but not statistically significant.

\section{DISCUSSION}

Overall, the analysis revealed that the means of the systolic, diastolic, and mean arterial blood pressures to are be higher in the group without a patent ductus arteriosus when compared to the group with a patent ductus arteriosus. This finding was not proved to be statistically significant. Both groups had a difference of only $0-5 \mathrm{~mm}$ $\mathrm{Hg}$ in all parameters of blood pressures. In theory, the patient with a patent ductus arteriosus would demonstrate a lower blood pressure due to failed compensatory mechanisms. In the first 2 days of life, the infant without a patent ductus would drop their systolic blood pressures secondary to a decrease in total body volume. Thus the infant will compensate through the baroreceptor reflex. This reflex would increase their cardiac output and stroke volume. The increase in stroke volume and cardiac output has a direct increase systolic blood pressures, diastolic blood pressures and mean arterial blood pressures [7]. In the patient with a patent ductus arteriosus, the cardiovascular system is not a completely closed cir- 
cuit. The PDA allows a shunt to exist from the arterial system to the pulmonary vascular system. The arterial system has an overall higher vascular tone when compared to the low vascular tone of the pulmonary bed. The shunting from the arterial bed to the pulmonary bed will lead to an overall decrease in vascular tone and lower blood pressures. Also, the patient with a patent ductus will have increased pulmonary overflow, left atrial overload and ventricular overload, which may lead to some heart failure [6]. This heart failure could lead to lower blood pressures from the decreased cardiac output and stroke volume $[6,8]$. The aim of this study was to prove that there existed a statistically significant difference in blood pressures between both groups since in clinical practice the observed differences are seen.

In this study it was observed, in both groups, that the mean pulse pressures were widened. According to the definition, a widened pulse pressure exists when the difference of systolic and diastolic blood pressure is greater than 15 to $25 \mathrm{~mm} \mathrm{Hg}$, in a premature infant (1). The group with a patent ductus had widened mean pulse pressures between 19 - $26 \mathrm{~mm} \mathrm{Hg}$ while the group without a patent ductus also had widened mean pulse pressures between $16-24 \mathrm{~mm} \mathrm{Hg}$. Although the analysis revealed it not to be statistically significant, this finding is still intriguing. In clinical practice, the patient with a widened pulse pressure is automatically thought to have a patent ductus arteriosus. The finding that both groups had similar widened pulse pressures would not support this thought. Although the theory of diastolic run-off from a patent ductus is currently taught to residents in hospital programs, it does not hold true according to this study. The large shunting of blood flow from the aorta to the pulmonary arterial bed [6] during diastole would cause this diastolic run off. This effect, of the diastolic run off, will decrease the peripheral vascular resistance and lead to a reduced diastolic blood pressure and thus a widening of the pulse pressures.

Identifying a ductus arteriosus in a preterm infant through clinical signs is still a challenge. One cannot rely only on clinical assessments of blood pressures for a definite sign of a patent ductus arteriosus in the prema- ture infant. Many studies have been performed to correlate widened pulse pressures with patent ductus arteriosus however none have proven so. The study may have been limited due to the small group sizes and/or the few blood pressure samples that were collected in the patients. This was a retrospective chart review and the data obtained was limited to what was documented in the electronic file. In the future, a study may be created to account for the power size and the data amount needed for each group.

\section{REFERENCES}

[1] Long, W.A. (1990) Fetal and neonatal cardiology. W.B. Saunders Company, Philadelphia.

[2] Zahka, K.G. and Erenberg, F. (2010) Fanaroff and Martin's neonatal-perinatal medicine, diseases of the Fetus and newborn (Chapter 45. Part 7 Congenital Defects). 9th Edition, Missouri, St. Louis.

[3] Bancalari, E.H. and Walsh, M.C. (2010) Fanaroff and Martin's neonatal-perinatal medicine, diseases of the Fetus and newborn (Chapter 44. Part 7 Bronchopulmonary Dysplasia). 9th Edition, Missouri, St. Louis.

[4] Ratner, I. (1985) Association of low systolic and diastolic blood pressure with significant patent ductus arteriosus in the very low birth weight infant. Critical Care Medicine, 13, 497-499.

[5] Evans, N. (1993) Diagnosis of patent ductus arteriosus in the preterm newborn. Archives of Disease in Childhood, 68, 58-61. doi:10.1136/adc.68.1_Spec_No.58

[6] Evans, N., et al. (1992) Effect of patency of the patent ductus arteriosus on blood pressure in very preterm infants. Archives of Disease in Childhood, 67, 169-173. doi:10.1136/adc.67.10 Spec No.1169

[7] Mohrman, D.E. and Heller, L.J. (2010). Regulation of arterial pressure (Chapter 9). In: Mohrman, D.E. and Heller, L.J. (Eds), Cardiovascular Physiology, 7th Edition, McGraw-Hill Company, New York. http://www.accessmedicine.com/content.aspx?aID=6553 $\underline{984}$

[8] Bray, J.J., Cragg, P.A., Macknight, A.D.C., Mills, R.G. and Taylor, D.W. (1989) Blood pressure. Lecture notes on human physiology. Blackwell, Oxford, 427-428. 